\title{
EZH2 promotes DNA replication by stabilizing interaction of POL $\delta$ and PCNA via methylation-mediated PCNA trimerization
}

\author{
Peng $\mathrm{A}^{1 \dagger}$, Xinyi $\mathrm{Xu}^{1 \dagger}$, Chenglin Wang ${ }^{1}$, Jing Yang ${ }^{1}$, Shida Wang ${ }^{1}$, Jiewen Dai ${ }^{2}$ and Ling Ye ${ }^{{ }^{*}}$
}

\begin{abstract}
Background: Proliferating cell nuclear antigen (PCNA), a ring-shaped homotrimer complex, promotes DNA replication via binding to DNA polymerase. Trimerized PCNA is critical for DNA replication. Enhancer of zeste homologue 2 $(\mathrm{EZH} 2)$, which primarily acts as a histone methyltransferase, is essential for proliferation. However, how EZH2 promotes proliferation by controlling DNA replication through PCNA remains elusive.

Results: Here, we showed that low EZH2 levels repressed the proliferation of human dental pulp cells (hDPCs). The EZH2 protein level was dramatically upregulated in hDPCs at S phase in the absence of H3K27 trimethylation. Molecularly, EZH2 interacted with PCNA via the PIP box and dimethylated PCNA at lysine 110. Dimethylation of PCNA is essential for stabilization of the PCNA trimer and the binding of DNA polymerase $\delta$ to PCNA.
\end{abstract}

Conclusions: Our data reveal the direct interaction between PCNA and EZH2 and a novel mechanism by which EZH2 orchestrates genome duplication.

Keywords: $\mathrm{EZH} 2, \mathrm{PCNA}$, DNA replication, Methylation

\section{Background}

Replication of the genome is an essential step in cell cycle progression and proliferation. Failure in this process will lead to abnormal cell proliferation, cell cycle arrest, and genomic instability [1-3]. At the heart of DNA replication, proliferating cell nuclear antigen (PCNA) has an essential role in orchestrating normal DNA synthesis by providing a platform to which DNA polymerases and other factors bind via the PIP box [4]. PCNA, a ringshaped sliding clamp, encircles DNA by the dimerization (prokaryotes) or trimerization (eukaryotes) of monomers [5-7]. Post-translational modifications (PTMs) of PCNA facilitate these protein interactions and are essential for the high processivity and accuracy of DNA synthesis. Modifications on PCNA, carried by "writers," profoundly regulate the interaction between PCNA and its partners.

\footnotetext{
*Correspondence: yeling@scu.edu.cn

${ }^{\dagger}$ Peng A and Xinyi Xu contributed equally to this work

${ }^{1}$ State Key Laboratory of Oral Diseases, West China School

of Stomatology, Sichuan University, Chengdu, People's Republic of China

Full list of author information is available at the end of the article
}

Phosphorylation, acetylation, ubiquitination, and sumoylation on PCNA have been strongly suggested to regulate DNA replication by affecting the binding affinity of PCNA partners or the stability of PCNA [8-11]. Additionally, SETD8, a methyltransferase, has been reported to interact with, and methylate PCNA $[12,13]$.

Protein lysine methylation has been widely elucidated in histone modification [14, 15]. However, accumulating non-histone proteins have been reported to be methylated by histone methyltransferases [16, 17]. Enhancer of zeste homologue 2 (EZH2), a methyltransferase, is primarily responsible for the trimethylation of histone H3 lysine 27 (H3K27me3) [18-21]. In addition, EZH2 has been reported to methylate non-histone proteins, such as cardiac transcription factor 4 (GATA4), retinoic acid-related orphan nuclear receptor $\alpha(R O R \alpha)$, and signal transducer and activator of transcription 3 (STAT3) [22-24]. EZH2 is positively related to proliferation, and its role as a transcriptional silencer via repression of INK4A/ARF is well established [25-27]. Beyond its role as the transcriptional repressor, EZH2 was also reported 
to localize at the replication fork by interacting with histone in response to DNA damage $[28,29]$. Moreover, a recent study suggests that Polycomb (PcG) repressive complexes (PRCs) control proliferation independent of transcriptional repression of cell cycle-regulating genes [30]. However, there is still a lack of evidence indicating whether EZH2 directly binds to PCNA, and information regarding whether EZH2 participates in DNA replication remains elusive.

In this study, we demonstrated, for the first time, that EZH2 directly binds to PCNA via the PIP box and promotes methylation at lysine 110 . Then, we showed that K110me2 is critical for the stabilization of the PCNA trimer. Finally, we showed that EZH2 promotes the interaction between DNA polymerase $\delta$ (POL $\delta$ ) and PCNA.

\section{Results}

\section{EZH2 regulates HDPC proliferation independent of its role} as a gene repressor

EZH2 is highly expressed in actively proliferating cells and controls cell proliferation by regulating cell cycle checkpoint signalling via histone methyltransferase activity $[25,26]$. First, we investigated how EZH2 influences proliferation through the regulation of checkpoint signalling in hDPCs. shRNA was used to knock down the expression of EZH2 in hDPCs (Fig. 1a). We observed that hDPC proliferation was strongly impaired upon EZH2 knockdown as indicated by the results of the colony formation assay and growth curves (Fig. 1b, c). Cells exhibited a reduction in the percentage of cells in $S$ phase. Interestingly, no significant increase in the percentage of cells in either G0/G1 phase or G2/M phase was observed (Fig. 1d). Our observation was contrary to previous studies in which EZH2 depletion led to an increase in the percentage of cells in G2/M phase [31,32].

To experimentally validate these observations, the expression of cell cycle-related genes was measured using a cell cycle RNA-sequencing assay in EZH2-knockdown hDPCs from three different donors. EZH2 has been reported to function as a transcriptional repressor [21] and represses the expression of INK4A, INK4B, and $A R F[27,33]$. In the RNA-sequencing analysis of EZH2knockdown hDPCs, eight genes were transcriptionally altered (Fig. 1e); however, there was no transcriptional difference in INK4A and ARF. Among the eight genes, cyclin-dependent kinase 2 (CDK2), cyclin E2 (CCNE2), and cyclin-dependent kinase inhibitor $2 \mathrm{~B}$ (CDKN2B, also known as $I N K 4 B$ ) are involved in controlling cell cycle phase transition [26, 34]. CDK2 and CCNE2, which also regulate the DNA replication process, were

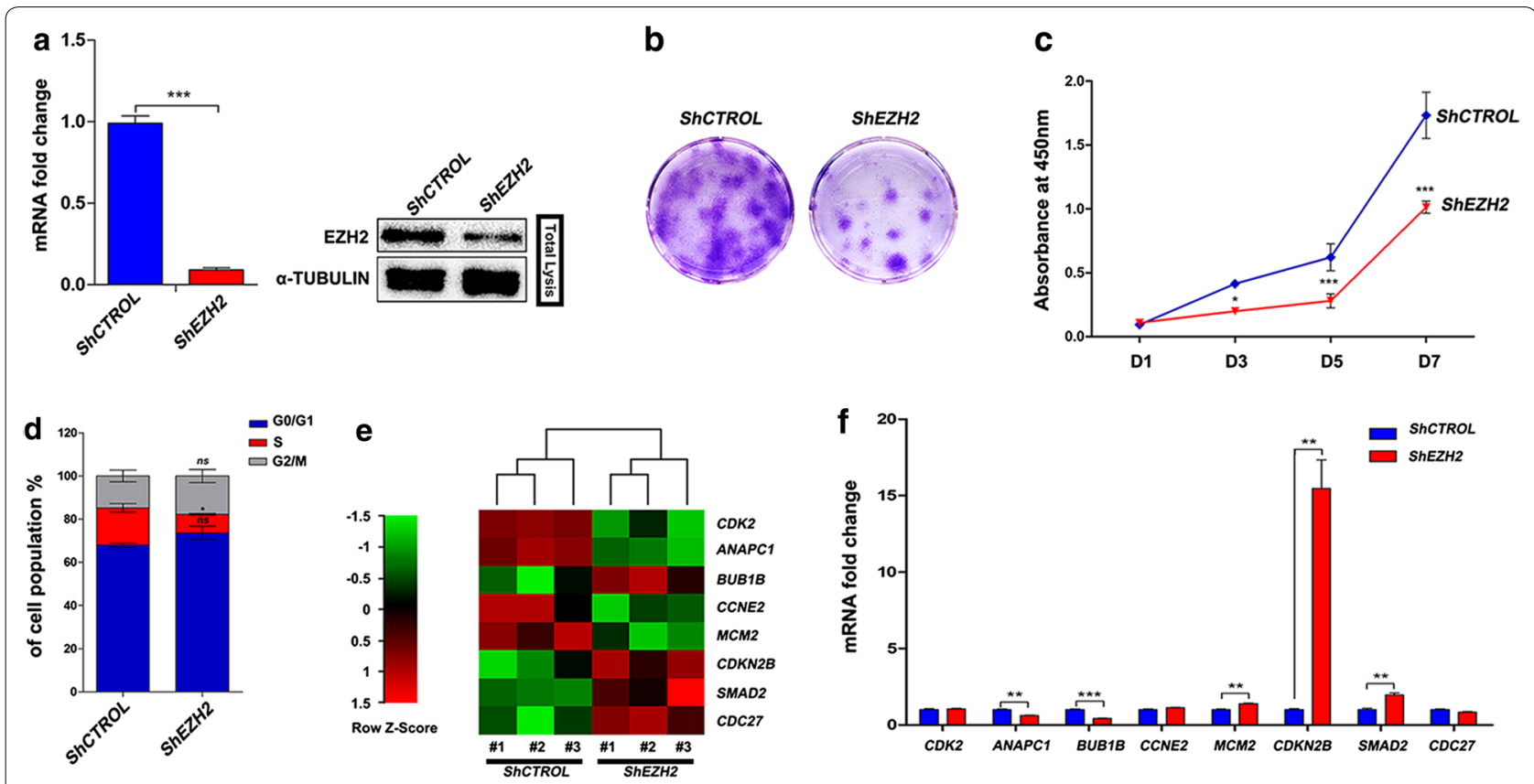

Fig. 1 EZH2-knockdown hDPCs show decreased proliferation, but no transcriptionally significant changes are observed in DNA replication-related genes. a Quantitative PCR and western blot show EZH2 knockdown with shRNA in hDPCs (72 h after transduction). b Colony formation assay by crystal violet staining demonstrates the viability of EZH2 knockdown hDPCs. c Growth curves measured with CCK-8. d Flow cytometry analysis shows the cell cycle distribution of EZH2-knockdown hDPCs. e Cell cycle RNA-sequencing assay shows the transcripts with significantly altered expression in EZH2-knockdown hDPCs. $f$ Quantitative PCR verifies the expression levels of genes identified in the RNA-Seq data. (ns not significant, $\left.{ }^{*} P<0.05,{ }^{* *} P<0.01,{ }^{* *} P<0.001\right)$ 
downregulated, and $C D K N 2 B$ was upregulated. Interestingly, when verifying the differentially expressed genes in the RNA-Seq data by qPCR in hDPCs from a fourth donor, we found that only $A N A P C 1, C D K N 2 B$, and $S M A D 2$ exhibited the same changes in gene expression (Fig. 1f). These findings are consistent with a previous study showing that Polycomb (PcG) controls the proliferation of mouse embryonic fibroblasts (MEFs) independent of Ink4a/Arf suppression [30].

Combined with the observation that the defect in proliferation upon EZH2 knockdown did not elicit significant cell cycle arrest at G1 or G2/M phase, our data suggest that instead of canonically controlling transcription at cell cycle phase transitions [27], EZH2 may regulate the proliferation of $\mathrm{hDPCs}$ with an alternative mechanism (Additional file 1: Figure S1).

EZH2 elevates at S phase in hDPCs and interacts with PCNA The proliferation of hDPCs was independent of EZH2 transcriptional activity (Fig. 1). In addition, a previous study showed that PRCs control the proliferation of MEFs instead of functioning in their traditional role as a transcriptional repressor [30]. Thus, we hypothesized that EZH2 could be directly involved in events during $\mathrm{S}$ phase. To investigate this, we first examined the expression dynamics of EZH2 in the cell cycle of hDPCs. hDPCs were synchronized at G0 phase by serum deprivation for $48 \mathrm{~h}$ and subsequently released from deprivation by the addition of $10 \%$ FBS to allow entry into the cell cycle (Fig. 2a). Then, cells were harvested at the indicated time points and subjected to flow cytometry to examine the cell cycle distribution (Additional file 2: Figure S2A); furthermore, the protein level of EZH2 was investigated at the indicated time points. We found that EZH2 protein accumulated at $\mathrm{S}$ phase $(24 \mathrm{~h})$; however, the levels of trimethylated histone H3 lysine 27 (H3K27me3) were decreased at S phase (Fig. 2b). Recently, studies reported a lower accumulation of H3K27me3 following DNA replication [35, 36], which is consistent with our observations. Immunofluorescence was performed at 8 and $24 \mathrm{~h}$, which correspond to G1 phase and S phase, respectively. Consistently, compared to the levels in G1 phase, EZH2 protein levels were increased and had accumulated in the nucleus during $\mathrm{S}$ phase (Fig. 2b, Additional file 2: Figure S2C left), and the accumulation was further confirmed by Pearson's correlation coefficient analysis of EZH2 and DAPI staining (Additional file 2: Figure S2C,

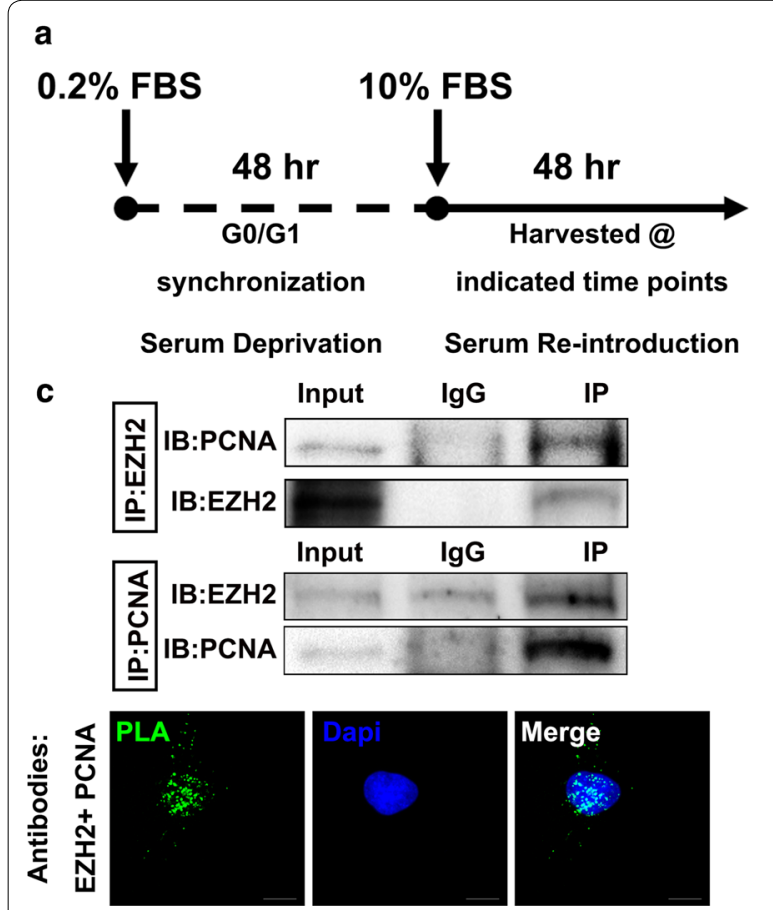

b
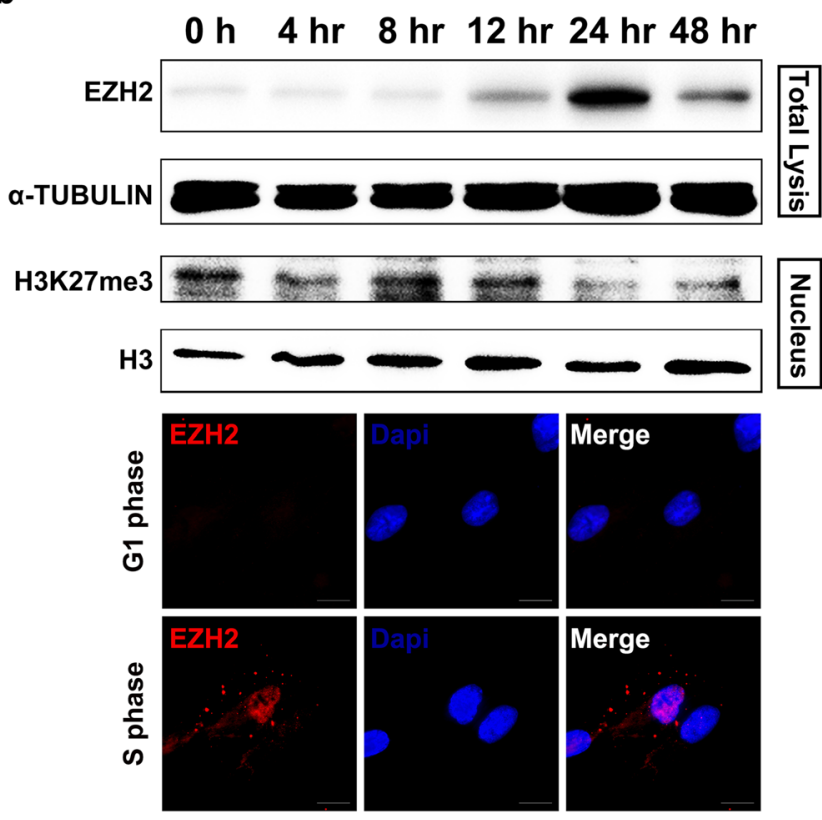

Fig. 2 EZH2 elevates at S phase in hDPCs and interacts with PCNA. a Schematic chart illustrating the serum deprivation approach used for G0/ G1 phase synchronization of hDPCs. b Western blot shows the expression of EZH2 in hDPCs at the indicated time points after release from serum deprivation. Immunofluorescence shows the subcellular localization of EZH2 in hDPCs in G1 or S phase. c Co-immunoprecipitation (Co-IP) of EZH2 and PCNA in hDPCs (synchronized at S phase) and proximity ligation assay (PLA) after co-incubating anti-EZH2 and anti-PCNA antibodies in hDPCS in S phase. IgGs were used as control antibodies for the IP. Antibodies used for IP and western blot are labelled as IP and IB, respectively. Total lysate $(10 \mu \mathrm{g})$ was used as an input control. Scale bars represent $20 \mu \mathrm{m}$ 
right). These data indicated a new role for $\mathrm{EZH} 2$ in the biological process of $\mathrm{S}$ phase independent of catalysing H3K27 trimethylation.

Because cells duplicate their genome during $S$ phase, we hypothesized that EZH2 might participate in the DNA replication of hDPCs in S phase. PCNA, a sliding clamp, is at the heart of DNA synthesis by providing the platform for factors to orchestrate DNA replication [4, 37]. Additionally, EZH2 has been reported to be present at the replication fork in human cells [29, 38]. Thus, we investigated whether EZH2 directly interacts with PCNA in hDPCs. We performed co-immunoprecipitation (co-IP) of endogenous EZH2 and PCNA (Fig. 2c, upper panel). Moreover, by using a proximity ligation assay (PLA) with EZH2- and PCNA-specific antibodies, we visualized the interaction of EZH2 and PCNA at the molecular level (Fig. 2c, lower panel). Additionally, the interaction of EZH2 and PCNA was verified in $293 \mathrm{~T}$ cells (data not shown). These results indicate that EZH2 directly interacts with PCNA and strongly indicates the participation of EZH2 in DNA replication.

\section{The presence of a PIP box in EZH2}

SET (SU [VAR] 3-9, Enhancer of Zeste, Trithorax)domain proteins usually bind to their catalytic substrates via the SET domain [39-41]. To investigate whether the binding of EZH2 to PCNA also occurs in a SET domain-dependent manner, we transfected $293 \mathrm{~T}$ cells with EZH2 $S$ SET (SET domain-truncated mutation) (Fig. 3a) and then examined the interaction between EZH2 and PCNA using IP in wild-type $E Z H 2$ - or EZH2 $\triangle S E T$-transfected $293 \mathrm{~T}$ cells. Interestingly, deletion of the SET domain showed no effect on the ability of PCNA to bind EZH2 (Fig. 3b), suggesting that the interaction between EZH2 and PCNA is governed by other mechanisms rather than the binding of the SET domain. PCNA has been reported to interact with other proteins via the evolutionally conserved PIP box [4, 42] or the AlkB homologue 2 PCNA-interacting motif (APIM) [43] present in those proteins.




Additionally, histone methyltransferases have also been reported to possess a PIP box motif to interact with PCNA $[12,44]$. Thus, we assessed whether EZH2 contains either a putative PIP box or the APIM. When surveying the amino acid sequence of EZH2, we found a conserved putative PIP box (RVLIGTYY) (Fig. 3c) but not the APIM motif. To determine whether EZH2 interacts with PCNA via the putative PIP box, we mutated the conserved amino acid residues isoleucine $(I)$ and tyrosine $(Y)$ in the PIP box to alanine $(A)$ residues (EZH2 $\triangle P I P)$ (Fig. 3d). Then, we performed IP with a FLAG-tagged antibody in $293 \mathrm{~T}$ cells transfected with wild-type $E Z H 2$ or EZH2 $P I P$. PCNA was precipitated in cells transfected with wild-type EZH2 but not in cells transfected with EZH2 $\triangle$ PIP (Fig. 3e). Taken together, these results strongly suggest that EZH2 is a novel PCNA-interacting protein and possesses an evolutionarily conserved PIP box.

\section{EZH2 methylates PCNA}

As a histone lysine methyltransferase, EZH2 promotes the addition of mono-, di- or trimethyl groups onto its histone substrates [18-20, 45]. Moreover, EZH2 has recently been reported to interact with non-histone proteins and to promote the methylation of non-histone proteins [22-24]. Additionally, because our data showed that EZH2 directly interacts with PCNA (Fig. 2), we hypothesize that PCNA might be a catalytic substrate of EZH2. To evaluate this, we first tested the methylation status of PCNA in hDPCs and 293T cells. Using IP with an anti-PCNA antibody in hDPCs and 293T cells followed by immunoblot with a pan-methyl lysine antibody, we found the presence of methylated lysines on PCNA in both hDPCs and 293T cells (Fig. 4a). Next, to investigate the role of EZH2 in PCNA methylation, we performed IP with a PCNA antibody in EZH2-knockdown hDPCs or 293T cells and then examined the methylation status of PCNA. In both cases, PCNA methylation was significantly decreased (Fig. 4b). These data suggested that

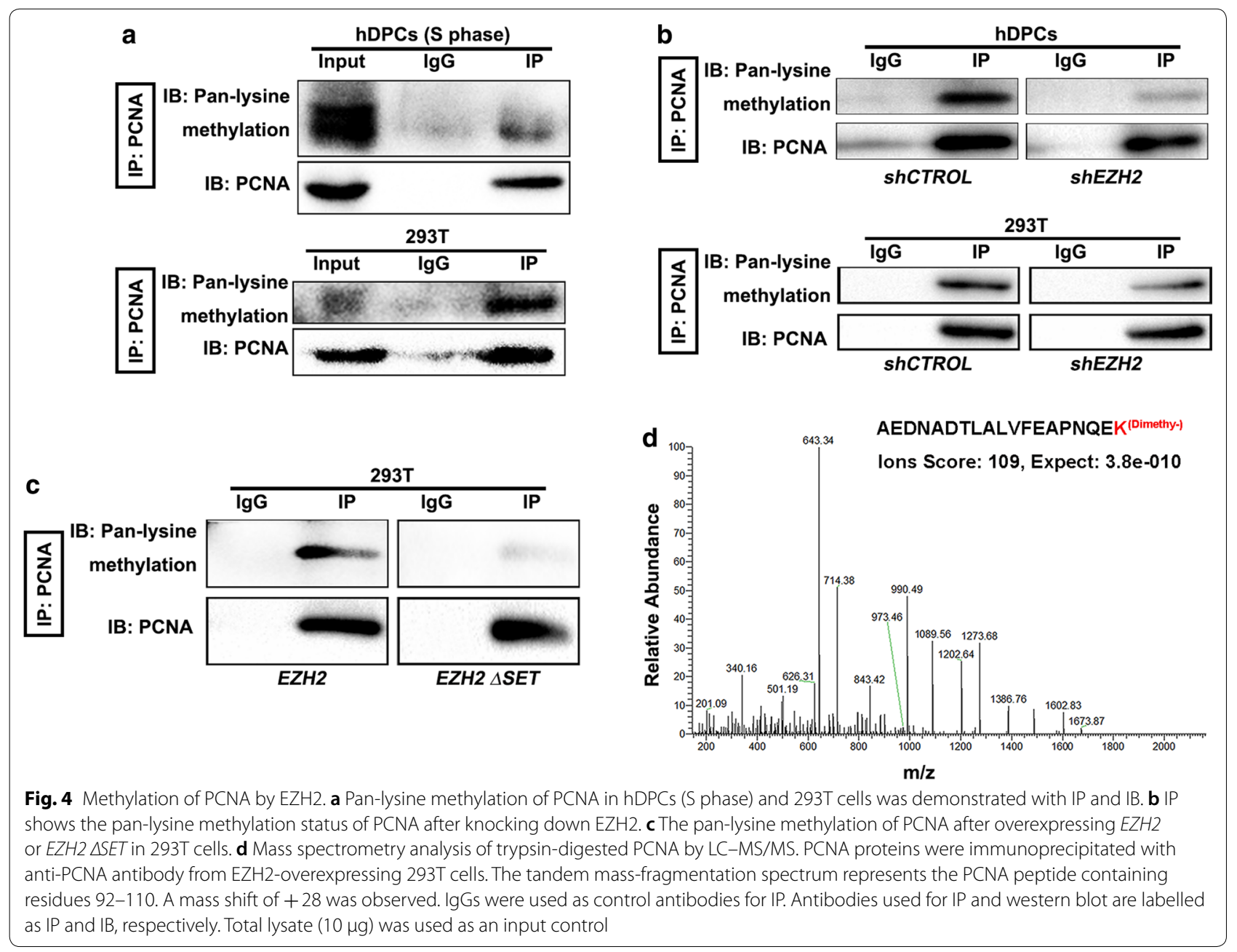


EZH2 is required for the lysine methylation of PCNA. To further determine whether the methyltransferase activity of EZH2 is necessary for PCNA methylation, we assessed the methylation status of endogenous PCNA in EZH2 $\triangle S E T$-transfected 293T cells. Compared to wildtype EZH2, EZH2 $\triangle S E T$-transfected 293T cells exhibited markedly decreased methylation of PCNA (Fig. 4c). Furthermore, to investigate the site at which EZH2 promoted methylation on PCNA, we overexpressed EZH2 in 293T cells, immunoprecipitated endogenous PCNA with an anti-PCNA antibody, and subjected the PCNA gel band to mass spectrometry analysis. A dimethyl modification was identified at the lysine (110) residue of PCNA (Fig. 4d). Taken together, our data suggested that PCNA is a catalytic substrate of EZH2 and is dimethylated at lysine 110 .

\section{Stabilized trimerization of PCNA by EZH2 is essential for the binding of DNA polymerase $\delta$ to PCNA}

As a scaffold for DNA polymerases, PCNA plays a crucial role in DNA synthesis $[37,46]$. Thus, we next investigated how EZH2 regulates DNA replication in hDPCs. First, we conducted an EdU pulse assay for $3 \mathrm{~h}$ in EZH2knockdown hDPCs. We found that fewer EZH2-knockdown hDPCs cells were actively synthesizing DNA than wild-type cells, as illustrated by the reduced EdU incorporation (Fig. 5a). PCNA, a ring-shaped clamp, consists of three homo-monomers arranged in a "head-to-tail" manner in eukaryotes $[5-7,47]$. Upon further exploration of the structure of PCNA, we identified that the methylated lysine residue is located on the $\beta$-sheet of the PCNA monomer where two monomers meet to establish the "head-to-tail" complex. We therefore hypothesized that EZH2 could regulate the stabilization of the trimer form of PCNA. We then applied a protein crosslink strategy to evaluate the stabilization of the PCNA trimers. EZH2 depletion reduced the formation of the PCNA trimer (Fig. 5b). We used the same crosslink strategy to investigate whether stabilization of the PCNA trimer was dependent on the protein methylation capacity of EZH2. Stabilization of the PCNA trimer was impaired in cells expressing either the SET domain-truncated mutation or the PIP box mutation (Fig. 5c). Taken together, our results indicate that EZH2 is essential for the stabilization of the PCNA trimer.

In normal DNA replication, enhancing the processivity of DNA polymerase $\delta$ (POL $\delta$ ) is the primary function of PCNA $[46,48,49]$. Thus, we explored whether EZH2 could affect the binding of POL $\delta$ to PCNA. First, we immunoprecipitated endogenous PCNA protein using a PCNA antibody to assess the interaction between POL $\delta$ (represented by the catalytic subunit, POLD1) and PCNA in hDPCs and 293T cells with EZH2 knockdown. We found decreased binding of POLD1 to PCNA when EZH2 was knocked down (Fig. 5d). We next investigated whether the binding of POL $\delta$ to PCNA depends on the interaction between EZH2 and PCNA by examining the interaction between PCNA and POL $\delta$ in EZH2 2 PIPtransfected 293T cells. We found that the binding of POLD1 to PCNA was dramatically reduced upon mutation of the PIP box (Fig. 5d). Moreover, we also investigated the effect of the methyltransferase activity of EZH2 on the interaction between PCNA and POL $\delta$. Compared to the cells expressing wild-type $E Z H 2$, cells transfected with EZH2 $\triangle S E T$ showed decreased levels of POLD1 precipitated with PCNA (Fig. 5d). Taken together, these results indicate that the methyltransferase activity of EZH2 is necessary for the interaction between PCNA and POL $\delta$.

As our data demonstrated that PCNA can undergo EZH2-mediated dimethylation at lysine 110, we hypothesized that K110me2 may affect the stabilization of the PCNA trimer. We introduced a point mutation at lysine 110 on PCNA (Fig. 5e), expressed this mutant in 293T cells, and then conducted the protein crosslink assay. As demonstrated, the trimer form of PCNA was dramatically impaired upon mutating PCNA at this residue (Fig. 5e). Moreover, the binding of POL $\delta$ to PCNA was dramatically impaired (Fig. 5e). Based on the fact that K110Amutated PCNA exhibited impaired binding to POL $\delta$, we next tested whether this mutant PCNA could affect DNA synthesis. By using a DNA fibre assay, we observed that the DNA length dramatically decreased in cells expressing PCNA with the K110A mutation (Fig. 5f).

\footnotetext{
(See figure on next page.)

Fig. 5 Methylation of PCNA at lysine 110 affects the binding of DNA polymerase $\delta$ to PCNA. a A 3 h EdU pulse was applied in EZH2-knockdown hDPCs at $21 \mathrm{~h}$ after release from serum deprivation. Scale bars represent $100 \mu \mathrm{m}$. b Formaldehyde protein crosslinking assay indicates the presence of the trimer form of PCNA in EZH2-depleted 293T cells. The left panel illustrates the location of lysine 110 on the "head" $\beta$-sheet of the interface between the homo-monomers. c Crosslink assay shows the level of the trimer form of PCNA in 293T cells overexpressing EZH2 $\triangle S E T$ and EZH2 $\triangle P I P$.

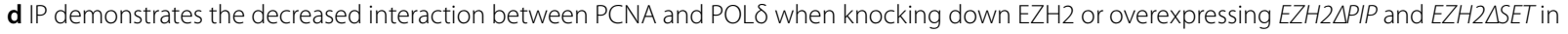
293T cells. e Schematic representation of full-length PCNA with a point mutation at lysine 110 (K1 10). A Myc tag was added on the C-terminus. The crosslink assay shows the level of trimer PCNA upon lysine 110 mutation (PCNA $\triangle$ ). IP demonstrates the binding of POL $\delta$ to PCNA when PCNA $\triangle$ is overexpressed in 293T cells. $\mathbf{f}$ DNA fibre assay demonstrates DNA synthesis in cells expressing the lysine 110 mutant (PCNA $)$. Origins are indicated by arrows. Scatter plot and bar chart show the DNA length (***< ${ }^{* 0.001) . ~ I g G s ~ w e r e ~ u s e d ~ a s ~ a ~ c o n t r o l ~ a n t i b o d y ~ f o r ~ I P s . ~ A n t i b o d i e s ~ u s e d ~ f o r ~ I P ~ a n d ~}$ western blot are labelled as IP and IB, respectively
} 

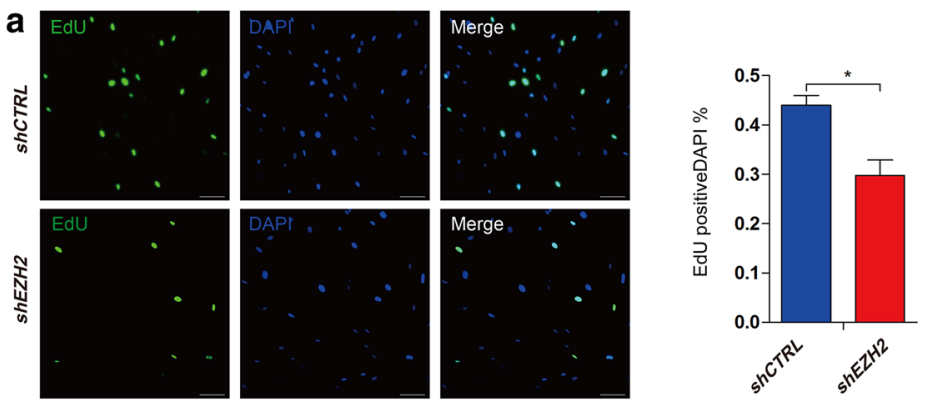

b
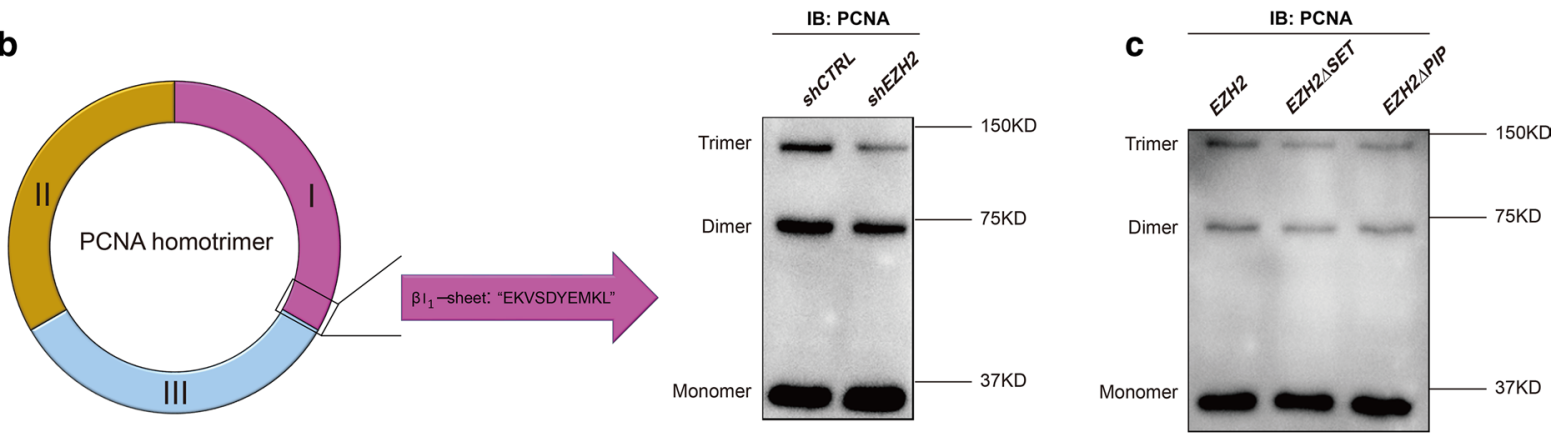

e
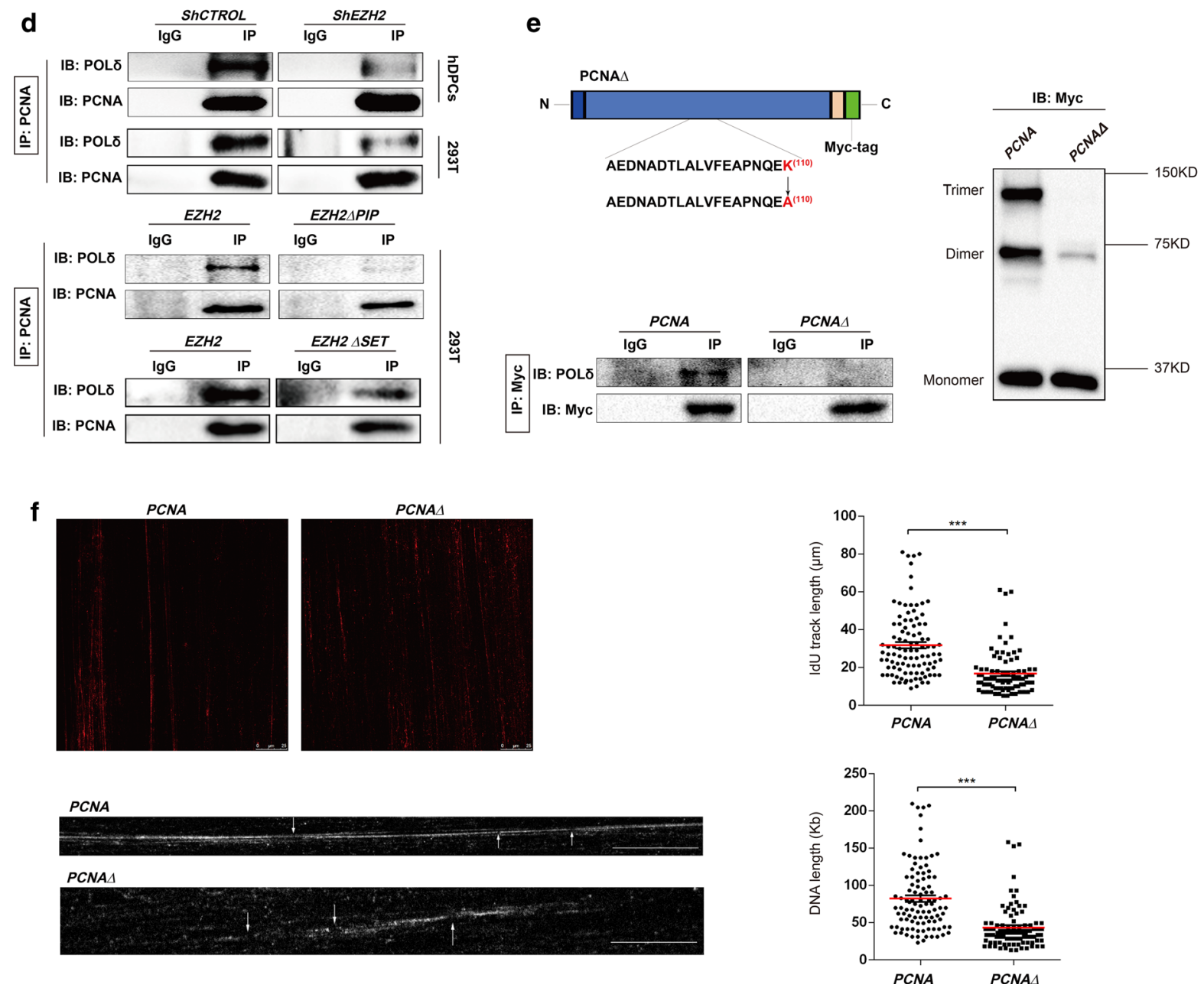
Taken together, our data suggested that the K110me2 catalysed by EZH2 is important for the trimerization of PCNA and the binding of POL $\delta$ to PCNA.

\section{Discussion}

Epigenetic modulators such as methyltransferases have been widely studied in the histone lysine methylation field with regard to their modulation of chromatin properties and regulation of gene expression [21, 50-52]. However, owing to growing interest in the post-translational modifications of proteins, the importance of methylation on non-histone proteins has frequently been indicated, and non-histone proteins have been reported to be potential substrates of histone lysine methyltransferases [16, 17]. In the present study, we demonstrated that PCNA is a novel substrate of EZH2 that can be dimethylated at K110. To date, only three non-histone proteins, ROR $\alpha$, GATA4, and STAT3, have been reported to be substrates of EZH2 [22-24]. In addition, lysine methylation is reversible, and H3K27 has been shown to be demethylated by KDM6B $[15,53]$. Thus, the occurrence of demethylation on PCNA and the verification of de-methyltransferase activity on PCNA need to be elucidated in future. Recently, studies have reported a lower accumulation of H3K27me3 following DNA replication [35, 36], which is consistent with our observation of decreased H3K27me3 in hDPCs in S phase.

In the present study, we found that knockdown of EZH2 did not induce a significant cell cycle arrest at G1 or G2/M phase, but the proliferation activity of hDPCs was continuously repressed. This was also supported by the observation that the transcript levels of most cell cycle regulatory genes did not change when EZH2 was knocked down in hDPCs. These findings are consistent with previous studies showing that Polycomb (PcG) controls the proliferation of MEFs independent of INK4A/ ARF suppression [30].

PCNA, a sliding clamp, plays a key role in duplicating the genome by providing a scaffold for relevant factors and DNA polymerases. PCNA interacts with DNA replication cofactors during DNA replication via the evolutionarily conserved PIP box or APIM motif $[4,43,54]$. Previous studies reported that the SET-domain proteins ATXR5 and ATXR6, which have primarily been demonstrated to be H3K27 mono-methyltransferases, interacted with PCNA in Arabidopsis [44, 55]. In addition, other epigenetic modifiers, such as DNMT1, HDAC1, p300, and SETD8, were reported to interact with PCNA in humans $[11,13,56,57]$. So far, SETD8 is the only histone methyltransferase that has been reported to methylate PCNA [13]. Furthermore, previous studies suggested that in response to DNA damage, EZH2 was recruited to stalled replication forks to function as an $\mathrm{H} 3 \mathrm{~K} 27 \mathrm{me} 3$ methyltransferase $[28,29]$. However, there was no evidence indicating a direct interaction between EZH2 and PCNA. Here, we provide the first evidence that EZH2 directly interacts with PCNA via the conserved PIP box motif to promote the methylation of PCNA. In the study by Andrea Piunti et al., the association between RING1B and PCNA is reduced in the absence of EZH2, suggesting the possible hierarchical recruitment of PRC1 and PRC2 [30, 58]. In our study, we confirmed the interaction between EZH2 and PCNA; thus, we hypothesized that the reduced association between RING1B and PCNA was possibly influenced by the diminished interaction between EZH2 and PCNA when EZH2 was depleted. However, this mechanism needs to be verified in future.

PCNA, a ring-shaped complex, consists of three homomonomers that assemble in a "head-to-tail" manner in eukaryotes [4]. Maintenance of the PCNA trimer is a prerequisite for promoting the processivity of DNA polymerase $\delta$ (POL $\delta)$. Here, we uncovered that PCNA K110me2 catalysed by EZH2 is essential for stabilizing the trimer form of PCNA. Moreover, consistent with previous studies [30, 59], we observed an interaction between SUZ12 and PCNA (data not shown). This suggested that other PRC2 components might be involved in the regulation of PCNA methylation. The trimerization of PCNA is established through the binding of $\beta$-sheets of each monomer at the interfaces between the subunits $[5,6,60]$. Three types of interactions between the monomer interfaces of PCNA have been proposed to stabilize the PCNA trimer: hydrogen bonds, hydrophobic interactions, and ion pairs. Among these, ion pairs between the $\beta$-sheets and the interface were considered the main contributor [60]. Based on the investigation of PCNA among various species, a positive polar amino acid, lysine, was found at position 110, which is located within the $\beta$-sheet [60]. Here, we report that K110me2 is critical for the trimerization of PCNA. Methylation does not perturb the charge of the lysine residue and induces a small change in its size; thus, K110me2 is more likely to enhance the hydrophobic interaction between the monomers to stabilize the PCNA trimer by changing the hydrogen property and hydrophobic force of lysine 110 [17, 60, 61]. To verify this hypothesis, further structural studies are needed. Moreover, in normal DNA replication, PCNA interacts with POL $\delta$ and stimulates its processing activity $[4,47,62,63]$. Here, we claimed that EZH2-mediated dimethylation of PCNA K110 is essential for the interaction of PCNA with POL $\delta$, leading to the control of DNA synthesis. Because EZH2 regulates the trimerization of PCNA, it is evident that the binding of POL $\delta$ to PCNA decreases in the absence of EZH2.

\section{Conclusion}

In conclusion, our results provide novel evidence that PCNA is a novel lysine methylation substrate of EZH2 and that EZH2 is a new PCNA-interacting protein. 
EZH2-dependent dimethylation of PCNA K110 is essential for DNA replication because it affects the binding of POL $\delta$ to PCNA via stabilization of the PCNA trimer (Fig. 6). There experiments reveal a novel mechanism through which epigenetic regulators participate and control DNA replication.

\section{Methods}

\section{Cell culture}

hDPCs were harvested from normal impacted third molars extracted from adult humans (19-22 years old) in West China Hospital of Stomatology as described previously [64]. The procedures were approved by the
Ethical Committee of the West China School of Stomatology, Sichuan University, and performed in accordance with approved guidelines; all subjects provided informed consent. HEK293T (ATCC) cells were obtained from Ohio (Shanghai). In all experiments, cells were grown in DMEM (GIBCO) supplemented with 10\% FBS (GIBCO) and $1 \%$ antibiotics (GIBCO). HEK293T cells were cultured in growth medium on plates coated with $0.01 \%$ poly-L-lysine (Sigma-Aldrich). All cells were grown at $37^{\circ} \mathrm{C}$ in a humidified atmosphere containing $5 \% \mathrm{CO}_{2}$.

For G0/G1 synchronization, hDPCs were grown in $0.2 \%$ FBS-containing medium for $48 \mathrm{~h}$, after which they

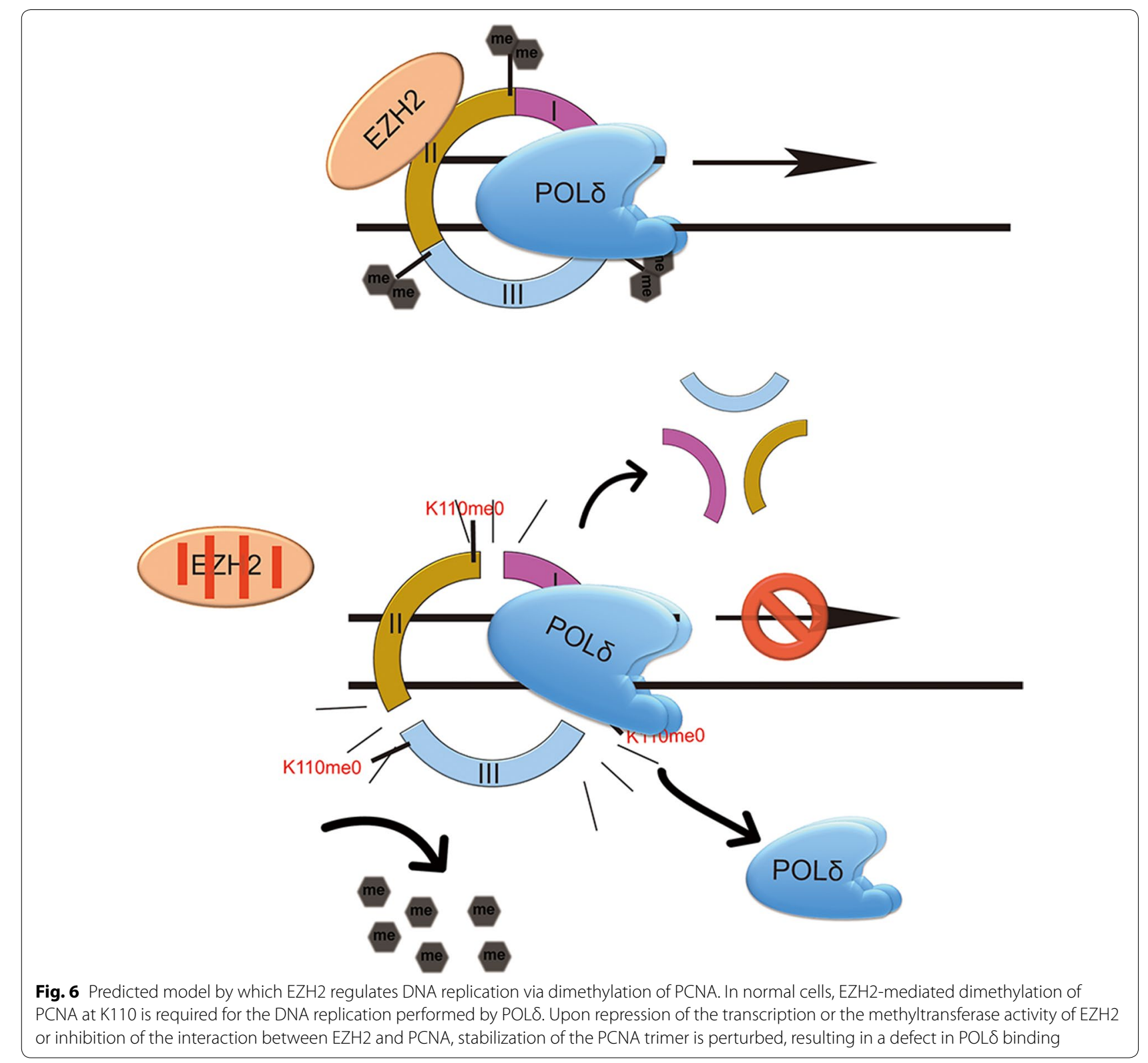


were cultured in normal growth medium and harvested at the indicated time points.

\section{Lentivirus production and transduction}

Lentivirus expressing shEZH2 (forward oligo: 5'-CCGG GAGGGAAAGTGTATGATAACTCGAGTTATCATAC ACTTTCCCTCTTTTTG-3', reverse oligo: 5'-AATTCA AAAA GAGGGAAAGTGTATGATAACTCGAGTTA TCATACACTTTCCCTC-3') was generated by inserting shRNA oligos against EZH2 into the pLKO.1-TRC cloning vector (gifts from Zhipeng Fan, Capital Medical University) following the Addgene protocol. Oligos were synthesized by Invitrogen. The control vector was also a gift from Zhipeng Fan. Constructs containing wild-type $E Z H 2, E Z H 2 \triangle S E T$, PIP box point mutations of EZH2 (EZH2 $\triangle P I P)$, wild-type PCNA, or point mutations of PCNA (PCNAA) were acquired from Ohio (Shanghai). Lentiviruses containing shRNA were produced in 293T cells with the following plasmids: $9 \mu \mathrm{g}$ of pLKO.1 shRNA vector, $6 \mu \mathrm{g}$ of $\Delta 8.2$ packaging plasmid, and $3 \mu \mathrm{g}$ of VSV-G envelope plasmid. After $60 \mathrm{~h}$, the supernatant containing viral particles was harvested and filtered at $0.45 \mu \mathrm{m}$ and added to either hDPCs or 293T cells in the presence of $5 \mu \mathrm{g} / \mathrm{ml}$ polybrene (Sigma-Aldrich) for $48 \mathrm{~h}$. Then, positive cells were selected with $2 \mu \mathrm{g} / \mathrm{ml}$ puromycin (Sigma-Aldrich) for 3 days, and the cells were maintained in growth medium containing $1 \mu \mathrm{g} / \mathrm{ml}$ puromycin.

\section{Western blot analysis}

For immunoblots, cells were lysed in protein lysis solution (Pierce Biotechnology) containing protease inhibitor cocktail (Millipore) and phosphatase inhibitor cocktails (Millipore). Protein extraction was performed according to the manufacturer's instructions. For nuclear protein detection, a nuclear extraction procedure was applied following the manufacturer's protocol (Pierce Biotechnology). After the proteins were subjected to standard SDS-polyacrylamide gel (SDS-PAGE) electrophoresis (the percentages were based on the molecular weight of proteins of interest), they were transferred to nitrocellulose membranes (Millipore), which were blocked for $1 \mathrm{~h}$ at room temperature in TBST $(0.1 \%$ Tween- 20$)$ containing either $5 \%$ skim milk or bovine serum albumin (SigmaAldrich). Then, the membranes were incubated overnight at $4{ }^{\circ} \mathrm{C}$ with primary antibodies diluted in blocking buffer, washed 5X with TBST, and incubated for $1 \mathrm{~h}$ in secondary antibodies diluted in blocking buffer (Table 1). Membranes were washed with Restore Western Blot Stripping Buffer (Thermo) following the manufacturer's protocol. Next, the membranes were washed 5X with TBST, and enhanced chemiluminescence reagent (Millipore) was added to the membranes. Proteins were visualized using
ImageLab (Bio-Rad) according to the manufacturer's instructions (Additional file 3: Figure S3).

\section{Cell proliferation assays Growth curves}

hDPCs were seeded in 96-well plates at a density of $3 \times 10^{3}$ cells per well in triplicate for each time point, and the medium was changed every 2 days. To determine the cell viability, a 7-day time course was implemented, and a 10- $\mu$ l CCK-8 solution (Dojindo) was added every 2 days and incubated for $1.5 \mathrm{~h}$ according to the manufacturer's protocol. The absorbance at $450 \mathrm{~nm}$ was measured by a microplate reader (BioTek) and normalized to the background readings.

\section{Colony formation assay}

hDPCs were seeded in a six-well plate at a density of 500 cells/well and cultured in growth medium for 3 wks. Cells were washed with PBS, fixed in a $4 \%$ paraformaldehyde for $5 \mathrm{~min}$, and then stained with crystal violet (Beyotime) for $5 \mathrm{~min}$.

\section{Flow cytometry analysis}

To analyse the cell cycle distribution, trypsinized cells were washed with PBS and fixed in ice-cold $70 \%$ ethanol overnight. Cells were then washed $2 \mathrm{X}$ with PBS and incubated with RNase for $30 \mathrm{~min}$ at $37^{\circ} \mathrm{C}$ followed by incubation with propidium iodide (PI) (KeyGEN Biotech) for $30 \mathrm{~min}$ at $4{ }^{\circ} \mathrm{C}$. The PI-stained cells were examined on a Guava EasyCyte HT flow cytometer (Millipore) and analysed with InCyte2.7 software (Millipore).

\section{RNA-sequencing analysis}

hDPCs from three different donors were collected, treated with TRIzol (Invitrogen) and subjected to cell cycle RNA sequencing (RiboBio) to detect the transcripts of cell cycle-related genes. Array and data were performed and analysed by RiboBio Inc. (Guangzhou). Genes with an expression fold change $\geq 1.5$ and $P \leq 0.05$ were considered differentially expressed. RNA-Seq data are available upon demand from the corresponding author.

\section{qPCR}

Total RNA was extracted using TRIzol (Invitrogen) according to the manufacturer's protocol. Reverse transcription was performed with a PrimeScript ${ }^{\circledR} \mathrm{RT}$ reagent kit with gDNA Eraser (TaKaRa). Quantitative real-time PCR was carried out using a standard SYBR Green PCR kit (TaKaRa) on a CFX96 (Bio-Rad). Glyceraldehyde3-phosphate dehydrogenase (GAPDH) was used to normalize the expression level of each gene. Primer pairs for each gene were as follows: 
GAPDH: 5'-CGGAGTCAACGGATTTGGTCGTAT $-3^{\prime}$ and $5^{\prime}$-AGCCTTCTCCATGGTGGTGAAGAC $-3^{\prime}$;

EZH2: $\quad 5^{\prime}$-GCCAGACTGGGAAGAAATCTG-3' and $5^{\prime}$-TGTGCTGGAAAATCCAAGTCA-3'; CDK2: 5'-GGCACGTACGGAGTTGTGTA-3' and 5'-CTCAGTCTCAGTGTCCAGGC-3';

ANAPC1: $\quad 5^{\prime}$-AGGCCTGCGAAGGAAACTTA-3' and 5'-ACGTTGACACGGACAGGATG-3'; CDKN2B: 5'-GAATGCGCGAGGAGAACAAG-3' and 5'-CATCATCATGACCTGGATCGC-3'; SMAD2: 5'-GCTTCCCTCGTGCTGATTGG-3' and 5'-GTATGGAAGACGGAGGGAGC-3';

CCNE2: $\quad 5^{\prime}$-GGCCTATATATTGGGTTGGCG-3' and $5^{\prime}$-ACGGCTACTTCGTCTTGACA-3'; MCM2: 5'-ATCTACGCCAAGGAGAGGGT- ${ }^{\prime}$ and 5'-GTAATGGGGATGCTGCCTGT-3';

BUB1B: 5'-GGATGGGTCCTTCTGGAAAC- $3^{\prime}$ and 5'-AAGCTCCCCAAGAACAGACA-3'; CDC27: 5'-GACAGCTCCACAACCAAGGA-3' and 5'-TCAAACCTTCTGCTGCTGCT-3'.

\section{Immunofluorescence staining}

hDPCs were seeded on coverslips overnight before serum deprivation. Cells were fixed with $4 \%$ paraformaldehyde in PBS at room temperature for $15 \mathrm{~min}$ and then permeabilized with $0.5 \%$ Triton X-100 in PBS for 20 min at room temperature. Cells were blocked for 30 min with blocking buffer (Zhongshanjinqiao) and incubated overnight at $4{ }^{\circ} \mathrm{C}$ with primary antibodies in blocking solution. Coverslips were washed $5 \mathrm{X}$ with PBST $(0.5 \%$ Tween-20) and incubated for $1 \mathrm{~h}$ at room temperature with fluorescent secondary antibodies (Table 1). Next, the coverslips were washed $5 \mathrm{X}$ with PBST (0.5\% Tween-20) and then stained with 4'6-diamidino-2-phenylindole (DAPI) to identify nuclear DNA. Images were captured on a Nikon Eclipse 300 fluorescence microscope (CompixInc). ImageJ was used to calculate Pearson's correlation coefficient and Mender's coefficient of colocalization.

\section{5-Ethynyl-2'-deoxyuridine (EdU) staining}

EdU staining was conducted using an EdU imaging kit (RiboBio) according to the manufacturer's protocol. Briefly, hDPCs were seeded on coverslips overnight followed by serum starvation. Then, cells were released from deprivation in complete growth medium for $24 \mathrm{~h}$, during which an EdU pulse was applied for $3 \mathrm{~h}$ at a concentration of $50 \mu \mathrm{M}$. After labelling, cells were stained with EdU. For double staining with other antigens, additional immunohistochemical staining was performed following EdU staining before the nuclei were stained with DAPI. Images were captured with a Nikon Eclipse 300 fluorescence microscope (CompixInc).

\section{Proximity ligation assay}

Cells were prepared as described in the immunofluorescence section and incubated with anti-EZH2 (Goat) and anti-PCNA (mouse) primary antibodies following the manufacturer's instructions (Sigma-Aldrich). Briefly, cells were incubated for $60 \mathrm{~min}$ at $37^{\circ} \mathrm{C}$ with anti-mouse PLUS (Sigma-Aldrich, DUO92001) and anti-Goat MINUS (Sigma-Aldrich, DUO92006), washed twice with Buffer A (Sigma-Aldrich, DUO82047), and then incubated with the ligation solution (Sigma-Aldrich, DUO92014) for $30 \mathrm{~min}$ at $37^{\circ} \mathrm{C}$. After ligation, cells were washed twice with Buffer A and then incubated for $100 \mathrm{~min}$ at $37^{\circ} \mathrm{C}$ with amplification reagents (Sigma-Aldrich, DUO92014). Finally, the cells were washed three times with Buffer B (Sigma-Aldrich, DUO82048), stained, and mounted with mounting medium (Sigma-Aldrich, DUO82040) to visualize the nuclei. Images were captured with a Nikon Eclipse 300 fluorescence microscope (CompixInc).

\section{Immunoprecipitation}

Cells were harvested at the indicated times, lysed in lysis buffer supplemented with a protease inhibitor cocktail, incubated on ice for $20 \mathrm{~min}$, and cleared by centrifugation at $14,000 \mathrm{rpm}$ at $4{ }^{\circ} \mathrm{C}$ for $20 \mathrm{~min}$. Total protein lysate $(500 \mu \mathrm{g})$ was incubated with agarose-conjugated protein A/G beads for $2 \mathrm{~h}$ at $4{ }^{\circ} \mathrm{C}$; the lysate was washed $5 \mathrm{X}$ with PBS at $4{ }^{\circ} \mathrm{C}$ and centrifuged at $14,000 \mathrm{rpm}$ at $4{ }^{\circ} \mathrm{C}$ for $20 \mathrm{~min}$. Then, the lysate was subjected to immunoprecipitation with agarose (Beyotime)-immobilized antibodies or isotype control antibodies overnight at $4{ }^{\circ} \mathrm{C}$. The mix was washed $3 \mathrm{X}$ with lysis buffer at $4{ }^{\circ} \mathrm{C}$. The precipitated proteins were subjected to SDS-PAGE and detected by western blot.

\section{Formaldehyde crosslinking}

Formaldehyde crosslinking assays were performed as previously described [65]. Trypsinized cells were resuspended and incubated in a $1.0-1.5 \%$ formaldehyde solution at room temperature for $30 \mathrm{~min}$. Then, the reaction was quenched by the addition of a $1.5 \mathrm{M}$ glycine solution to a final concentration of $0.15 \mathrm{M}$ and incubated at room temperature for $5 \mathrm{~min}$. Cells were pelleted by centrifugation at $4000 \mathrm{rpm}$ at room temperature for $5 \mathrm{~min}$ and resuspended and washed twice in PBS. Products were analysed by western blot using PCNA (PC10) or Myctagged antibodies.

\section{DNA fibre assay}

A DNA fibre assay was performed according to a previous study [66]. Briefly, 293T cells were labelled with $25 \mu \mathrm{M}$ IdU (Sigma-Aldrich, I17125) for $2 \mathrm{~h}$. A $2-\mu \mathrm{l}$ cell suspension was spotted at the end of the microscope 
slide and incubated with $7 \mu \mathrm{l}$ of lysis buffer (0.5\% SDS, $200 \mathrm{mM}$ Tris- $\mathrm{HCl}$ (pH 7.4), and $50 \mathrm{mM}$ EDTA) for $2 \mathrm{~min}$. Slides were tilted $15^{\circ}$ to allow the DNA fibres to stretch along the slide and then allowed to air-dry. After 10 min of fixation in methanol:acetic acid (3:1), the DNA was denatured with $2.5 \mathrm{M} \mathrm{HCl}$ for $60 \mathrm{~min}$ and blocked in $5 \%$ BSA in PBS (Table 1).

Slides were incubated with primary antibodies (antiIdU), washed three times in PBS, incubated with secondary antibodies, and mounted.

\section{Statistical analysis}

The statistical analysis of the RNA sequencing was calculated with ANOVA, whereas the statistical analysis of other experiments was carried out with Student's $t$ test (two-tailed) using Prism 5 (GraphPad Software). Error bars represent the standard deviation (SD). $P$ values $<0.05$ were considered statistically significant. ${ }^{*} P<0.05, \quad * P<0.01$, and ${ }^{* * *} P<0.001$. All experiments were repeated three times biologically unless specifically indicated.

\section{Additional files}

Additional file 1: Figure S1 (related to Fig. 1). A: Immunoblot shows the H3K27me3 level in EZH2-knockdown hDPCs. B: The morphology of hDPCs with EZH2 knockdown. C: Quantification of colony-forming ability of hDPCs with EZH2 knockdown. D: Charts represent genes in the cell cycle RNA-sequencing assay that are involved in DNA replication based on the AmiGO 2 database. (ns not significant, ${ }^{*} P<0.05,{ }^{* *} P<0.01,{ }^{* * *} P<0.001$ ). Scale bar represents $100 \mu \mathrm{m}$

Additional file 2: Figure S2 (related to Fig. 2). A: Flow cytometry shows the cell cycle distribution of hDPCs from one donor at the indicated time points after release from serum deprivation. B: Immunoblot demonstrates the expression of CYCLIN D1 and CYCLIN A2, indicating G1 phase and S phase, respectively. a-TUBULIN was used a loading control of whole lysate. C: Statistical analysis of the EZH2-positive ratio (Left, $n=3$ ) and Pearson's correlation coefficient of EZH2 with DAPI (right, each dot represents one cell). D: Statistical analysis of the PLA-positive ratio (left, $n=5$ ). The PLA signals are associated with DAPI on a single-cell basis $\left({ }^{* * *} P<0.001\right)$

Additional file 3: Figure S3. Uncut immunoblots from the immunoprecipitation experiments

\section{Authors' contributions}

PA formed the conception, designed the experiments, drafted, and revised this article. XX performed experiments, interpreted data, and revised this article. CW, JY, SW, and JD revised the manuscript. LY revised the work critically. All authors read and approved the final manuscript.

Table 1 Antibodies used in this study

\begin{tabular}{|c|c|c|c|c|}
\hline Antibody & Brand & Cat no. & Use & Condition \\
\hline $\mathrm{EZH} 2$ & $\mathrm{BD}$ & 612666 & WB, IF & $1: 2000,1: 200$ \\
\hline $\mathrm{EZH} 2(\mathrm{AC22})$ & Merck Millipore & $17-662$ & $\mathbb{I P}$ & $2 / 500 \mu \mathrm{g}$ \\
\hline $\mathrm{EZH} 2$ & $R \& D$ & AF4767 & PLA & $1: 50$ \\
\hline Histone H3 & Abcam & ab24834 & WB & $1: 1000$ \\
\hline a-Tubulin & Abcam & ab52866 & WB, IF & $1: 5000,1: 500$ \\
\hline H3K27me3(C36B11) & Cell signalling & 9733 & WB & $1: 2000$ \\
\hline PCNA (PC10) & Cell signalling & 2586 & $W B, I F, P L A, I P$ & $1: 5000,1: 200$ \\
\hline Pan-methyl lysine & Abcam & $a b 7315$ & WB & $1: 2000$ \\
\hline DNA Polymerase delta (607) & Abcam & ab10362 & WB & $1: 1000$ \\
\hline CYCLIN A2 & Abcam & ab38 & WB & $1: 500$ \\
\hline CYCLIN D1 & Abcam & ab40754 & WB & $1: 5000$ \\
\hline FLAG-tag & Sigma & F7425 & WB, IP & $1: 2000,1: 100$ \\
\hline Myc-Tag & Cell signalling & 2278 & $W B, I P$ & $1: 4000,1: 200$ \\
\hline Ubiquityl-PCNA (Lys 164) (D5C7P) & Cell signalling & 13439 & WB & $1: 1000$ \\
\hline Histone $\mathrm{H} 2 \mathrm{AX}$ & Abcam & Ab11175 & WB & $1: 2500$ \\
\hline$Y-H 2 A . X$ & Cell signalling & 9718 & WB & $1: 2000$ \\
\hline Goat anti-rabbit lgG (HRP) & Abcam & ab6721 & WB & $1: 10,000$ \\
\hline Goat anti-mouse lgG (HRP) & Abcam & ab6789 & WB & $1: 10,000$ \\
\hline Rabbit anti-goat IgG-FITC & Boster & BA1110 & IF & $1: 60$ \\
\hline Rabbit anti-goat lgG-Cy3 & Boster & BA1034 & IF & $1: 60$ \\
\hline Goat anti-mouse lgG-Cy3 & Boster & BA1031 & IF & $1: 60$ \\
\hline Goat anti-mouse lgG-FITC & Boster & BA1101 & IF & $1: 60$ \\
\hline Goat anti-rabbit lgG-Cy3 & Boster & BA1032 & IF & $1: 60$ \\
\hline $\begin{array}{l}\text { Donkey anti-mouse lgG }(\mathrm{H}+\mathrm{L}) \text { (Alexa Fluor } \\
555)\end{array}$ & Beyotime & A0460 & IF & $1: 500$ \\
\hline Anti-IdU & Novus & NBP2-44056 & DNA fibre & $1: 300$ \\
\hline
\end{tabular}




\section{Author details}

${ }^{1}$ State Key Laboratory of Oral Diseases, West China School of Stomatology, Sichuan University, Chengdu, People's Republic of China. ${ }^{2}$ Shanghai Ninth People's Hospital, Shanghai Jiao Tong University School of Medicine, Shanghai, People's Republic of China.

\section{Acknowledgements}

We would like to thank Dr. Zhipeng Fan from Capital Medical University for kindly providing pLKO.1 plasmids. We would like to thank Dr. Wantae Kim, Dr. Prem Swaroop Yadav from Department of Developmental Biology, Harvard School of Dental Medicine for support and advice.

\section{Competing interests}

The authors declare that they have no competing interests.

\section{Availability of data and materials}

The datasets in this study are available from the corresponding author on reasonable request.

\section{Consent for publication}

Not applicable.

\section{Ethics approval and consent to participate}

All procedures followed were in accordance with the ethical standards of the responsible committee on human experimentation West China School of Stomatology, Sichuan University. Informed consent was obtained from all patients for being included in the study.

\section{Funding}

This work was supported by the National High-tech R\&D Program (863 Program) (No. 2015AA020306), the Sichuan Province Science and Technology Support Program (Grant Numbers. 2016JY0022), the National Natural Science Foundation of China (Grant Numbers. 81271127, 81322013), and the Program of International Science and Technology Cooperation (Grant Number. 2014DFA31990).

\section{Publisher's Note}

Springer Nature remains neutral with regard to jurisdictional claims in published maps and institutional affiliations.

Received: 24 April 2018 Accepted: 25 July 2018

Published online: 02 August 2018

\section{References}

1. Barretina J, Caponigro G, Stransky N, Venkatesan K, Margolin AA, Kim S, Wilson CJ, Lehar J, Kryukov GV, Sonkin D, et al. The cancer cell line encyclopedia enables predictive modelling of anticancer drug sensitivity. Nature. 2012;483:603-7.

2. Casimiro MC, Crosariol M, Loro E, Li Z, Pestell RG. Cyclins and cell cycle control in cancer and disease. Genes Cancer. 2012;3:649-57.

3. Champeris Tsaniras S, Kanellakis N, Symeonidou IE, Nikolopoulou P, Lygerou Z, Taraviras S. Licensing of DNA replication, cancer, pluripotency and differentiation: an interlinked world? Semin Cell Dev Biol. 2014;30:174-80.

4. Moldovan GL, Pfander B, Jentsch S. PCNA, the maestro of the replication fork. Cell. 2007;129:665-79.

5. Krishna TS, Fenyo D, Kong XP, Gary S, Chait BT, Burgers P, Kuriyan J. Crystallization of proliferating cell nuclear antigen (PCNA) from Saccharomyces cerevisiae. J Mol Biol. 1994;241:265-8.

6. Krishna TS, Kong XP, Gary S, Burgers PM, Kuriyan J. Crystal structure of the eukaryotic DNA polymerase processivity factor PCNA. Cell. 1994;79:1233-43.

7. Kong XP, Onrust R, O'Donnell M, Kuriyan J. Three-dimensional structure of the beta subunit of E. coli DNA polymerase III holoenzyme: a sliding DNA clamp. Cell. 1992;69:425-37.

8. Hoege C, Pfander B, Moldovan GL, Pyrowolakis G, Jentsch S. RAD6dependent DNA repair is linked to modification of PCNA by ubiquitin and SUMO. Nature. 2002;419:135-41.
9. Mailand N, Gibbs-Seymour I, Bekker-Jensen S. Regulation of PCNAprotein interactions for genome stability. Nat Rev Mol Cell Biol. 2013;14:269-82.

10. Watanabe K, Tateishi S, Kawasuji M, Tsurimoto T, Inoue H, Yamaizumi M. Rad18 guides pol eta to replication stalling sites through physical interaction and PCNA monoubiquitination. EMBO J. 2004;23:3886-96.

11. Hasan S, Hassa PO, Imhof R, Hottiger MO. Transcription coactivator p300 binds PCNA and may have a role in DNA repair synthesis. Nature. 2001:410:387-91.

12. Jorgensen S, Elvers I, Trelle MB, Menzel T, Eskildsen M, Jensen ON, Helleday T, Helin K, Sorensen CS. The histone methyltransferase SET8 is required for S-phase progression. J Cell Biol. 2007;179:1337-45.

13. Takawa M, Cho HS, Hayami S, Toyokawa G, Kogure M, Yamane Y, Iwai Y, Maejima K, Ueda K, Masuda A, et al. Histone lysine methyltransferase SETD8 promotes carcinogenesis by deregulating PCNA expression. Cancer Res. 2012;72:3217-27.

14. Greer EL, Shi Y. Histone methylation: a dynamic mark in health, disease and inheritance. Nat Rev Genet. 2012;13:343-57.

15. Black JC, Van Rechem C, Whetstine JR. Histone lysine methylation dynamics: establishment, regulation, and biological impact. Mol Cell. 2012;48:491-507

16. Biggar KK, Li SS. Non-histone protein methylation as a regulator of cellular signalling and function. Nat Rev Mol Cell Biol. 2015;16:5-17.

17. Hamamoto R, Saloura V, Nakamura Y. Critical roles of non-histone protein lysine methylation in human tumorigenesis. Nat Rev Cancer. 2015;15:110-24.

18. Czermin B, Melfi R, McCabe D, Seitz V, Imhof A, Pirrotta V. Drosophila enhancer of Zeste/ESC complexes have a histone $\mathrm{H3}$ methyltransferase activity that marks chromosomal Polycomb sites. Cell. 2002;111:185-96.

19. Cao R, Wang L, Wang H, Xia L, Erdjument-Bromage H, Tempst P, Jones RS, Zhang Y. Role of histone H3 lysine 27 methylation in Polycomb-group silencing. Science. 2002;298:1039-43.

20. Kuzmichev A, Nishioka K, Erdjument-Bromage H, Tempst P, Reinberg D. Histone methyltransferase activity associated with a human multiprotein complex containing the Enhancer of Zeste protein. Genes Dev. 2002;16:2893-905.

21. Cao R, Zhang $Y$. The functions of $E(Z) / E Z H 2$-mediated methylation of lysine 27 in histone H3. Curr Opin Genet Dev. 2004;14:155-64.

22. Lee JM, Lee JS, Kim H, Kim K, Park H, Kim JY, Lee SH, Kim IS, Kim J, Lee M, et al. EZH2 generates a methyl degron that is recognized by the DCAF1/ DDB1/CUL4 E3 ubiquitin ligase complex. Mol Cell. 2012;48:572-86.

23. Kim E, Kim M, Woo DH, Shin Y, Shin J, Chang N, Oh YT, Kim H, Rheey J, Nakano I, et al. Phosphorylation of EZH2 activates STAT3 signaling via STAT3 methylation and promotes tumorigenicity of glioblastoma stemlike cells. Cancer Cell. 2013;23:839-52.

24. He A, Shen X, Ma Q, Cao J, von Gise A, Zhou P, Wang G, Marquez VE, Orkin SH, PU WT. PRC2 directly methylates GATA4 and represses its transcriptional activity. Genes Dev. 2012;26:37-42.

25. Varambally S, Dhanasekaran SM, Zhou M, Barrette TR, Kumar-Sinha C, Sanda MG, Ghosh D, Pienta KJ, Sewalt RG, Otte AP, et al. The polycomb group protein $\mathrm{EZH} 2$ is involved in progression of prostate cancer. Nature. 2002;419:624-9.

26. Bracken AP, Pasini D, Capra M, Prosperini E, Colli E, Helin K. EZH2 is downstream of the pRB-E2F pathway, essential for proliferation and amplified in cancer. EMBO J. 2003;22:5323-35.

27. Bracken AP, Kleine-Kohlbrecher D, Dietrich N, Pasini D, Gargiulo G, Beekman C, Theilgaard-Monch K, Minucci S, Porse BT, Marine JC, et al. The Polycomb group proteins bind throughout the INK4A-ARF locus and are disassociated in senescent cells. Genes Dev. 2007;21:525-30.

28. Chou DM, Adamson B, Dephoure NE, Tan X, Nottke AC, Hurov KE, Gygi SP, Colaiacovo MP, Elledge SJ. A chromatin localization screen reveals poly (ADP ribose)-regulated recruitment of the repressive polycomb and NuRD complexes to sites of DNA damage. Proc Natl Acad Sci USA. 2010;107:18475-80

29. Rondinelli $B$, Gogola $E$, Yucel $H$, Duarte AA, van de Ven $M$, van der Sluijs R, Konstantinopoulos PA, Jonkers J, Ceccaldi R, Rottenberg S, et al. EZH2 promotes degradation of stalled replication forks by recruiting MUS81 through histone H3 trimethylation. Nat Cell Biol. 2017;19:1371-8.

30. Piunti A, Rossi A, Cerutti A, Albert M, Jammula S, Scelfo A, Cedrone L, Fragola G, Olsson L, Koseki H, Testa G. Polycomb proteins control 
proliferation and transformation independently of cell cycle checkpoints by regulating DNA replication. Nat Commun. 2014;5:3649.

31. Wu Z, Lee ST, Qiao Y, Li Z, Lee PL, Lee YJ, Jiang X, Tan J, Aau M, Lim CZ, et al. Polycomb protein EZH2 regulates cancer cell fate decision in response to DNA damage. Cell Death Differ. 2011;18:1771-9.

32. Gonzalez ME, Li X, Toy K, DuPrie M, Ventura AC, Banerjee M, Ljungman M, Merajver SD, Kleer CG. Downregulation of EZH2 decreases growth of estrogen receptor-negative invasive breast carcinoma and requires BRCA1. Oncogene. 2009;28:843-53.

33. Kotake Y, Cao R, Viatour P, Sage J, Zhang Y, Xiong Y. pRB family proteins are required for $\mathrm{H} 3 \mathrm{~K} 27$ trimethylation and Polycomb repression complexes binding to and silencing p16INK4alpha tumor suppressor gene. Genes Dev. 2007:21:49-54

34. Hanahan D, Weinberg RA. The hallmarks of cancer. Cell. 2000;100:57-70.

35. Petruk S, Cai J, Sussman R, Sun G, Kovermann SK, Mariani SA, Calabretta B, McMahon SB, Brock HW, lacovitti L, et al. Delayed Accumulation of H3K27me3 on nascent DNA is essential for recruitment of transcription factors at early stages of stem cell differentiation. Mol Cell. 2017;66:247-57.

36. Petruk S, Sedkov Y, Johnston DM, Hodgson JW, Black KL, Kovermann SK, Beck S, Canaani E, Brock HW, Mazo A. TrxG and PcG proteins but not methylated histones remain associated with DNA through replication. Cell. 2012;150:922-33.

37. Bravo R, Frank R, Blundell PA, Macdonald-Bravo H. Cyclin/PCNA is the auxiliary protein of DNA polymerase-delta. Nature. 1987;326:515-7.

38. Hansen KH, Bracken AP, Pasini D, Dietrich N, Gehani SS, Monrad A, Rappsilber J, Lerdrup M, Helin K. A model for transmission of the H3K27me3 epigenetic mark. Nat Cell Biol. 2008;10:1291-300.

39. Trievel RC, Beach BM, Dirk LM, Houtz RL, Hurley JH. Structure and catalytic mechanism of a SET domain protein methyltransferase. Cell. 2002;111:91-103.

40. Zhang X, Tamaru H, Khan SI, Horton JR, Keefe L, Selker EU, Cheng X. Structure of the neurospora SET domain protein DIM-5, a histone H3 lysine methyltransferase. Cell. 2002;111:117-27.

41. Dillon SC, Zhang X, Trievel RC, Cheng X. The SET-domain protein superfamily: protein lysine methyltransferases. Genome Biol. 2005;6:227.

42. Warbrick E. PCNA binding through a conserved motif. BioEssays News Rev Mol Cell Dev Biol. 1998;20:195-9.

43. Gilljam KM, Feyzi E, Aas PA, Sousa MM, Muller R, Vagbo CB, Catterall TC, Liabakk NB, Slupphaug G, Drablos F, et al. Identification of a novel, widespread, and functionally important PCNA-binding motif. J Cell Biol. 2009:186:645-54.

44. Raynaud C, Sozzani R, Glab N, Domenichini S, Perennes C, Cella R, Kondorosi E, Bergounioux C. Two cell-cycle regulated SET-domain proteins interact with proliferating cell nuclear antigen (PCNA) in arabidopsis. Plant J Cell Mol Biol. 2006:47:395-407.

45. Kogure M, Takawa M, Saloura V, Sone K, Piao L, Ueda K, Ibrahim R, Tsunoda T, Sugiyama M, Atomi Y, et al. The oncogenic polycomb histone methyltransferase $\mathrm{EZ} \mathrm{H} 2$ methylates lysine 120 on histone $\mathrm{H} 2 \mathrm{~B}$ and competes ubiquitination. Neoplasia. 2013;15:1251-61.

46. Ducoux M, Urbach S, Baldacci G, Hubscher U, Koundrioukoff S, Christensen J, Hughes P. Mediation of proliferating cell nuclear antigen (PCNA)-dependent DNA replication through a conserved p21(Cip1)-like PCNA-binding motif present in the third subunit of human DNA polymerase delta. J Biol Chem. 2001;276:49258-66.

47. Campbell S, Ismail IH, Young LC, Poirier GG, Hendzel MJ. Polycomb repressive complex 2 contributes to DNA double-strand break repair. Cell Cycle. 2013;12:2675-83.

48. Bruning JB, Shamoo Y. Structural and thermodynamic analysis of human PCNA with peptides derived from DNA polymerase-delta p66 subunit and flap endonuclease-1. Structure. 2004;12:2209-19.

49. Li H, Xie B, Zhou Y, Rahmeh A, Trusa S, Zhang S, Gao Y, Lee EY, Lee MY. Functional roles of $\mathrm{p} 12$, the fourth subunit of human DNA polymerase delta. J Biol Chem. 2006;281:14748-55.

50. Gerik KJ, Li X, Pautz A, Burgers PM. Characterization of the two small subunits of Saccharomyces cerevisiae DNA polymerase delta. J Biol Chem. 1998;273:19747-55.

51. Schuettengruber B, Chourrout D, Vervoort M, Leblanc B, Cavalli $\mathrm{G}$. Genome regulation by polycomb and trithorax proteins. Cell. 2007;128:735-45.
52. Strahl $B D$, Allis $C D$. The language of covalent histone modifications. Nature. 2000;403:41-5.

53. Schuettengruber B, Bourbon HM, Di Croce L, Cavalli G. Genome regulation by polycomb and trithorax: 70 years and counting. Cell. 2017;171:34-57.

54. Shi Y, Lan F, Matson C, Mulligan P, Whetstine JR, Cole PA, Casero RA, Shi Y. Histone demethylation mediated by the nuclear amine oxidase homolog LSD1. Cell. 2004;119:941-53.

55. Warbrick E. PCNA binding through a conserved motif. BioEssays News Rev Mol Cell Dev Biol. 1998;20:195-9.

56. Jacob Y, Feng S, LeBlanc CA, Bernatavichute YV, Stroud H, Cokus S, Johnson LM, Pellegrini M, Jacobsen SE, Michaels SD. ATXR5 and ATXR6 are H3K27 monomethyltransferases required for chromatin structure and gene silencing. Nat Struct Mol Biol. 2009;16:763-8.

57. Chuang LSH, lan HI, Koh TW, Ng HH, Xu GL, Li BFL. Human DNA (cytosine-5) methyltransferase PCNA complex as a target for p21(WAF1). Science. 1997;277:1996-2000.

58. Milutinovic S, Zhuang QL, Szyf M. Proliferating cell nuclear antigen associates with histone deacetylase activity, integrating DNA replication and chromatin modification. J Biol Chem. 2002;277:20974-8.

59. Barrero MJ, Izpisua Belmonte JC. Polycomb complex recruitment in pluripotent stem cells. Nat Cell Biol. 2013;15:348-50.

60. Leung KHT, Abou El Hassan M, Bremner R. A rapid and efficient method to purify proteins at replication forks under native conditions. BioTechniques. 2013;55:204-6.

61. Kelman Z, O'Donnell M. Structural and functional similarities of prokaryotic and eukaryotic DNA polymerase sliding clamps. Nucleic Acids Res. 1995;23:3613-20

62. Smith BC, Denu JM. Chemical mechanisms of histone lysine and arginine modifications. Biochem Biophys Acta. 2009;1789:45-57.

63. Garg P, Burgers PMJ. DNA polymerases that propagate the eukaryotic DNA replication fork. Crit Rev Biochem Mol. 2005;40:115-28.

64. Riva F, Savio M, Cazzalini O, Stivala LA, Scovassi IA, Cox LS, Ducommun B, Prosperi E. Distinct pools of proliferating cell nuclear antigen associated to DNA replication sites interact with the p125 subunit of DNA polymerase delta or DNA ligase I. Exp Cell Res. 2004;293:357-67.

65. Gronthos S, Mankani M, Brahim J, Robey PG, Shi S. Postnatal human dental pulp stem cells (DPSCs) in vitro and in vivo. Proc Natl Acad Sci USA. 2000;97:13625-30.

66. Schwab RA, Niedzwiedz W. Visualization of DNA replication in the vertebrate model system DT40 using the DNA fiber technique. J Vis Exp JoVE. 2011;56:3255.

Ready to submit your research? Choose BMC and benefit from:

- fast, convenient online submission

- thorough peer review by experienced researchers in your field

- rapid publication on acceptance

- support for research data, including large and complex data types

- gold Open Access which fosters wider collaboration and increased citations

- maximum visibility for your research: over $100 \mathrm{M}$ website views per year

At BMC, research is always in progress.

Learn more biomedcentral.com/submissions 